\title{
InToxicaÇÃo de Eucalipto SubMetido À Deriva Simulada de DIFERENTES HERBICIDAS ${ }^{1}$
}

\author{
Intoxication of Eucalyptus Submitted to Different Herbicide Drift
}

\author{
TUFFI SANTOS, L.D. ${ }^{2}$, FERREIRA, L.R. ${ }^{3}$, FERREIRA, F.A. ${ }^{3}$, DUARTE, W.M. ${ }^{4}$, TIBURCIO, R.A.S. ${ }^{5}$ \\ e MACHADO, A.F.L. ${ }^{2}$
}

\begin{abstract}
RESUMO - Além do glyphosate, amplamente usado, outros herbicidas, como o triclopyr e o carfentrazone-ethyl, apresentam potencial de uso na eucaliptocultura. Entretanto, a não-seletividade destes herbicidas ao eucalipto pode levar à intoxicação da cultura, caso haja contato das folhas com a calda aplicada. Objetivou-se avaliar os efeitos da deriva de alguns herbicidas em plantas de Eucalyptus urophylla, simulada por meio de subdoses: 0, 43,2, 86,4 e 172,8 $\mathrm{g} \mathrm{ha}^{-1}$ de glyphosate; 14,4, 28,8 e 57,6 $\mathrm{g} \mathrm{ha}^{-1}$ de triclopyr; 0,84, 1,68 e 3,36 $\mathrm{g} \mathrm{ha}^{-1} \mathrm{de}$ carfentrazone-ethyl; e das misturas: 43,2 $\mathrm{g} \mathrm{ha}^{-1}$ de glyphosate $+14,4 \mathrm{~g} \mathrm{ha}^{-1}$ de triclopyr; 86,4 $\mathrm{g} \mathrm{ha}^{-1}$ de glyphosate $+28,6 \mathrm{~g}^{\text {ha-1 }}$ de triclopyr; 43,2 $\mathrm{g} \mathrm{ha}^{-1}$ de glyphosate $+1,68 \mathrm{~g} \mathrm{ha}^{-1}$ de carfentrazoneethyl; 86,4 $\mathrm{g} \mathrm{ha}^{-1}$ de glyphosate $+3,36 \mathrm{~g} \mathrm{ha}^{-1}$ de carfentrazone-ethyl. As mudas de eucalipto com aproximadamente $50 \mathrm{~cm}$ de altura receberam a aplicação dos herbicidas de modo a não atingir o terço superior das plantas, 45 dias após o transplantio. Entre os tratamentos, a deriva de glyphosate mostrou-se mais danosa ao eucalipto, seguida de carfentrazone-ethyl e triclopyr. Plantas de eucalipto expostas à subdose de $172,8 \mathrm{~g}$ ha ${ }^{-1}$ de glyphosate e às misturas glyphosate + carfentrazone-ethyl tiveram maior porcentagem de intoxicação e menor crescimento aos 15, 30 e 45 dias após aplicação (DAA). Houve recuperação das plantas expostas à deriva do triclopyr, que apresentaram 56,25 e 15,10\% de intoxicação aos 15 e 30 DAA, respectivamente, indicando menor risco da deriva do triclopyr em comparação aos demais herbicidas e misturas estudados.
\end{abstract}

Palavras-chave: glyphosate, carfentrazone-ethyl, triclopyr, tecnologia de aplicação.

\begin{abstract}
Besides glyphosate, which is widely utilized, other herbicides such as triclopyr and carfentrazone-ethyl, have a potential use in eucalypt plantations. However, the non-selective nature of these herbicides may lead to plant intoxication due to leaf contact during application. This work aims to evaluate the effects of some herbicides drift on Eucalyptus urophylla, simulated by applying the following subdoses: $0,43.2,86.4$ and $172.8 \mathrm{~g} \mathrm{ha}^{-1}$ of glyphosate; $14.4,28.8$ and $57.6 \mathrm{~g} \mathrm{ha}^{-1}$ of triclopyr; $0.84,1.68$ and $3.36 \mathrm{~g} \mathrm{ha}^{-1}$ of carfentrazone-ethyl; and the following mixtures: $43.2 \mathrm{~g} \mathrm{ha}^{-1}$ of glyphosate $+14.4 \mathrm{~g} \mathrm{ha}^{-1}$ of triclopyr; $86.4 \mathrm{~g} \mathrm{ha}^{-1}$ of glyphosate $+28.6 \mathrm{~g} \mathrm{ha}^{-1}$ of triclopyr; $43.2 \mathrm{~g} \mathrm{ha}^{-1}$ of glyphosate $+1.68 \mathrm{~g} \mathrm{ha}^{-1}$ of carfentrazone-ethyl; and $86.4 \mathrm{~g} \mathrm{ha}$ of glyphosate $+3.36 \mathrm{~g} \mathrm{ha}^{-1}$ of carfentrazone-ethyl. The seedlings, about $50 \mathrm{~cm}$ high, were applied the herbicides in such a way that their superior third was not reached 45 days after transference. Glyphosate drift caused the most damage to the plant, followed by carfentrazone-ethyl and triclopyr, respectively. Eucalypt plants exposed to a subdose of $172.8 \mathrm{~g} \mathrm{ha}^{-1}$ of glyphosate and to glyphosate + carfentrazone-ethyl mixtures, had the highest percentage of intoxication and the lowest growth during the evaluation periods. The plants exposed to triclopyr drift presenting 56.25 and 15.10\% of intoxication at 15 and 30 days after application, respectively, were recovered, indicating a lesser triclopyr drift risk, compared with the other herbicides and mixtures studied.
\end{abstract}

Keywords: glyphosate, carfentrazone-ethyl, triclopyr, application technology.

Recebido para publicação em 17.2.2006 e na forma revisada em 4.8.2006.

2 Doutorando em Fitotecnia, Departamento de Fitotecnia, Universidade Federal de Viçosa - DFT/UFV, 36570-000 Viçosa-MG. <ltuffi@yahoo.com.br>; ${ }^{3}$ Prof. do Departamento de Fitotecnia - DFT/UFV, Bolsista do CNPq; ${ }^{4}$ Graduando em Agronomia DFT/UFV, Bolsista PIBIC/DFT; ${ }^{5}$ Graduando em Engenharia Florestal, Departamento de Engenharia Florestal - DEF/UFV, Bolsista PIBIC/DEF. 


\section{INTRODUÇÃO}

Nas áreas plantadas com eucalipto, um dos grandes problemas enfrentados são as plantas daninhas, cujo manejo assume papel de destaque entre os tratos culturais, apresentando reflexos diretos no rendimento e nos custos de produção.

A interferência das plantas daninhas no eucalipto é mais acentuada nos dois primeiros anos de produção, porém, em algumas áreas, o controle estende-se até o final da cultura, o que se justifica por questões de operacionalidade na colheita e por ganhos na produtividade. A redução na produtividade, o elevado custo de controle, a grande demanda de mãode-obra e o impacto do controle químico no ambiente colocam as plantas daninhas na lista dos piores problemas da eucaliptocultura.

O manejo das plantas daninhas em florestas plantadas é realizado por métodos químicos e mecânicos, isolados ou combinados (Toledo et al., 2003). No caso das empresas florestais, que geralmente cultivam extensas áreas, não só a escassez de mão-de-obra, como a necessidade de atingir elevados índices de produtividade, dentro de padrões econômicos aceitáveis, têm levado ao aumento no uso da capina química como alternativa para redução dos custos de produção (Ribeiro, 1988).

Dentre os produtos utilizados, destaca-se o herbicida glyphosate. O N-(fosfonometil) glicina (glyphosate) é um herbicida sistêmico de ação total que inibe a enzima 5-enolpiruvil shiquimato-3-fosfato sintetase (EPSP sintetase ou EPSPS) e impede que a planta forme os aminoácidos fenilalanina, tirosina e triptofano, utilizados para a sintese de proteínas e, também, em alguns metabólitos secundários, como vitaminas, lignina e hormônios (Bradshaw et al., 1997).

Outro herbicida com potencial de uso em áreas florestais é o triclopyr, apesar de não estar registrado para o manejo de plantas daninhas em eucalipto. O éster butoxietílico do ácido 3,5,6-tricloro-2-piridiloxiacético (triclopyr) é um herbicida sistêmico com absorção foliar e radicular. É utilizado para o controle de plantas daninhas latifoliadas em pastagens e na cultura do arroz, podendo ser considerado boa opção no controle de plantas daninhas perenes, geralmente não controladas pelo glyphosate. Sua degradação no solo é rápida, com meia-vida de 20 a 45 dias, dependendo do tipo de solo e das condições climáticas. Em solos com pH mais baixo o seu grau de adsorção é mais elevado e a mobilidade é menor. Sua degradação ocorre mais rapidamente em condições de umidade e temperatura mais elevadas (Rodrigues \& Almeida, 2005).

Uma das novas moléculas registradas para o uso na cultura do eucalipto é o carfentrazoneethyl, com boa eficiência no controle de espécies daninhas tolerantes ao glyphosate, como a trapoeraba (Commelina spp.) (Corrêa \& Borges, 2000). O carfentrazone-ethyl pertence ao grupo químico das aril-triazolinonas, é absorvido pelas folhas e tem como mecanismo de ação a inibição da protoporfirinogênio oxidase (PPO ou PROTOX), enzima esta envolvida na rota biossintética da clorofila. Nas plantas sensiveis tratadas com o carfentrazone-ethyl ocorre acúmulo de protoporfirinogênio IX, que, na presença da luz, catalisa a formação do oxigênio singleto, responsável pela peroxidação dos lipídios das membranas celulares.

O glyphosate, o triclopyr e o carfentrazoneethyl são herbicidas não seletivos ao eucalipto, sendo o contato dessas moléculas com a cultura, principalmente via deriva, altamente indesejado. Entretanto, pouco se sabe sobre os efeitos da deriva desses diferentes herbicidas sobre a cultura do eucalipto. Nesse contexto, objetivou-se avaliar a intoxicação, bem como o crescimento, de plantas de eucalipto expostas à deriva simulada de glyphosate, triclopyr e carfentrazone-ethyl.

\section{MATERIAL E MÉTODOS}

O experimento foi realizado no Campo Experimental Diogo Alves de Mello, pertencente ao Departamento de Fitotecnia da Universidade Federal de Viçosa, entre os meses de maio e agosto de 2005.

Mudas padronizadas, oriundas de semente, de Eucalyptus urophylla, com aproximadamente 3 meses de idade e $30 \mathrm{~cm}$ de altura, foram plantadas em vasos preenchidos com $10 \mathrm{~L}$ de solo argiloso, adubados de acordo com as exigências da cultura. A adubação de cobertura foi feita com $12 \mathrm{~g}$ por vaso de N-P-K (20-5-20), parcelado em três vezes. As plantas 
foram deixadas em ambiente aberto, sem proteção, recebendo irrigações manuais diárias, de modo que mantivesse adequada disponibilidade de água.

Utilizou-se o delineamento em blocos casualizados, com quatro repetições, sendo cada vaso considerado uma parcela experimental. Os tratamentos testados foram as doses reduzidas de glyphosate, triclopyr, carfentrazoneethyl e a combinação destes herbicidas, de acordo com a Tabela 1 .

Os tratamentos com herbicidas foram aplicados 45 dias após o plantio das mudas, quando o eucalipto apresentava cerca de $50 \mathrm{~cm}$ de altura, de modo que não atingisse o terço superior das plantas. Na aplicação utilizouse pulverizador costal de precisão, munido de barra com dois bicos com pontas tipo leque TT1 10.02 espaçados de $0,5 \mathrm{~m}$, operando a $250 \mathrm{kPa}$ de pressão, aplicando $250 \mathrm{~L} \mathrm{ha}^{-1}$ de calda. No momento da aplicação dos herbicidas a umidade relativa do ar encontrava-se a $81 \%$ e a temperatura era de $23,5^{\circ} \mathrm{C}$, com ventos em velocidade inferior a $3 \mathrm{~km} \mathrm{~h}^{-1}$. As folhas das plantas de eucalipto permaneceram, 24 horas após a aplicação dos tratamentos, protegidas do contato com água da chuva ou irrigação, visando evitar a lavagem do produto.
Após a aplicação dos herbicidas, foram observadas, diariamente, alterações morfológicas na parte aérea das plantas. Aos 15, 30 e 45 dias após a aplicação (DAA), determinouse a porcentagem de intoxicação em relação à testemunha sem herbicida, em que 0\% corresponde à ausência de sintomas visiveis e 100\% à morte das plantas de eucalipto.

Para avaliar a existência de sinergismo entre os herbicidas, os dados referentes à porcentagem de intoxicação foram submetidos à análise segundo o modelo proposto por Flint et al. (1988), que oferece tratamento estatístico ao método de Colby (Colby, 1967), através de teste $t$ de significância de contrastes. Nesse método, o sinergismo é estimado pelo efeito da interação entre os fatores $\left(\mathrm{I}_{\mathrm{ij}}\right)$, que é calculado subtraindo-se da interação $\left(\mathrm{P}_{\mathrm{ij}}\right)$ os efeitos dos fatores isolados $\left(P_{i 0}\right.$ e $\left.P_{0 j}\right)$ e somando-se o efeito dos níveis 0 de cada fator $\left(P_{00}\right)\left(I_{i j}=P_{i j}-\right.$ $\left.\mathrm{P}_{\mathrm{i} 0}-\mathrm{P}_{0 \mathrm{j}}+\mathrm{P}_{00}\right)$. O valor da diferença, quando há antagonismo, é significativo e negativo; quando há sinergismo, é significativo e positivo. Quando a diferença é não-significativa, aceitase a hipótese de que os efeitos sejam aditivos.

Aos 45 DAA, obtiveram-se dados sobre a altura das plantas (região entre o coleto e o ápice das plantas) e o diâmetro do caule a $1 \mathrm{~cm}$ do solo. Posteriormente, procedeu-se ao corte

Tabela 1 - Doses dos herbicidas aplicadas em plantas de eucalipto, simulando a deriva de glyphosate, triclopyr e carfentrazoneethyl

\begin{tabular}{|c|c|c|}
\hline Tratamento & Dose p.a. $\left(\mathrm{g} \mathrm{ha}^{-1}\right)$ & $\%$ da Dose* \\
\hline testemunha & --- & --- \\
\hline glyphosate & 43,2 & $3 \%$ de $4 \mathrm{~L} \mathrm{ha}^{-1}$ de Roundup NA \\
\hline glyphosate & 86,4 & $6 \%$ de $4 \mathrm{~L} \mathrm{ha}^{-1}$ de Roundup NA \\
\hline glyphosate & 172,8 & $12 \%$ de $4 \mathrm{~L} \mathrm{ha}^{-1}$ de Roundup NA \\
\hline triclopyr & 14,4 & $3 \%$ de $1 \mathrm{~L} \mathrm{ha}^{-1}$ de Garlonf \\
\hline triclopyr & 28,8 & $6 \%$ de $1 \mathrm{~L} \mathrm{ha}^{-1}$ de Garlonf \\
\hline triclopyr & 57,6 & $12 \%$ de $1 \mathrm{Lha}^{-1}$ de Garlonf \\
\hline carfentrazone-ethyl & 12 & $3 \%$ de $0,70 \mathrm{~L} \mathrm{ha}^{-1}$ de Auroraf \\
\hline carfentrazone-ethyl & 24 & $6 \%$ de $0,70 \mathrm{~L} \mathrm{ha}^{-1}$ de Auroraf \\
\hline carfentrazone-ethyl & 48 & $12 \%$ de $0,70 \mathrm{~L} \mathrm{ha}^{-1}$ de Auroraf \\
\hline glyphosate + triclopyr & $43,2+14,4$ & 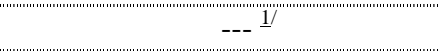 \\
\hline glyphosate + triclopyr & $86,4+28,8$ & "--- \\
\hline glyphosate + carfentrazone-ethyl & $43,2+12$ & "'--- \\
\hline glyphosate + carfentrazone-ethyl & $86,4+24$ & "'-"-- \\
\hline
\end{tabular}

* Doses recomendadas e utilizadas para o controle de grande número de plantas daninhas, tomadas como padrão.

1/ Mistura, feita no tanque de pulverização, dos produtos comerciais citados. 
da parte aérea das plantas e à separação das raízes do substrato, sendo ambas as partes acondicionadas em sacos de papel mantidos em estufa com circulação de ar $\left(65 \pm 3{ }^{\circ} \mathrm{C}\right)$ até atingir peso constante, para obtenção da massa seca da parte aérea e da raiz.

Em relação aos dados quantitativos, procedeu-se à análise de variância e ao teste de médias a $5 \%$ de probabilidade, utilizando-se o Aplicativo Computacional para Análises Genéticas e Estatísticas - GENES (Cruz, 1997).

\section{RESULTADOS E DISCUSSÃO}

Plantas tratadas com glyphosate apresentavam murcha, cloroses e necroses - sintomas verificados a partir do 6o dia após aplicação (DAA) - mais pronunciadas nas subdoses superiores a $172,8 \mathrm{~g} \mathrm{ha}^{-1}$ de glyphosate. Os sintomas foliares observados estão de acordo com os descritos por Tuffi Santos et al. (2005) para clones de eucalipto submetidos à deriva simulada de glyphosate. Sintomas semelhantes foram observados em outras culturas submetidas à deriva simulada com glyphosate, como milho (Magalhães et al., 2001) e algodão (Miller et al., 2004; Yamashita \& Guimarães, 2005).

Os sintomas observados em plantas expostas à aplicação do triclopyr e carfentrazoneethyl, vistos respectivamente aos 3 e 2 DAA, são mais precoces que os constatados em plantas tratadas com glyphosate. Os sintomas de intoxicação do triclopyr são caracterizados por retorcimento dos ápices e epinastia das folhas, ao passo que plantas pulverizadas com carfentrazone-ethyl apresentam folhas com necroses de coloração parda com formato arredondado a irregular, cujos bordos apresentam coloração arroxeada, provavelmente pelo acúmulo de compostos fenólicos.

Nas plantas sensíveis tratadas com o carfentrazone-ethyl ocorre acúmulo de protoporfirinogênio IX, que, na presença da luz, catalisa a formação do oxigênio singleto, responsável pela peroxidação das membranas. Com isso, tem-se rápida dessecação das plantas tratadas com os sintomas, podendo ser observáveis no mesmo dia da aplicação (Corrêa \& Burga, 2000).

Todas as plantas pulverizadas com $172,8 \mathrm{~g} \mathrm{ha}^{-1}$ de glyphosate e pela mistura de
$86,4 \mathrm{~g} \mathrm{ha}^{-1}$ de glyphosate $+24 \mathrm{~g} \mathrm{ha}^{-1} \mathrm{de}$ carfentrazone-ethyl apresentaram morte dos ponteiros. Entretanto, houve emissão de novas brotações, que, aos 45 DAA, se mostravam sadias em plantas tratadas com glyphosate, o que não foi observado em plantas expostas à mistura glyphosate + carfentrazone-ethyl, nas quais os sintomas de intoxicação persistiam.

A intoxicação das plantas variou de acordo com as subdoses dos herbicidas testados $(p<0,05)$ aos 15,30 e 45 DAA, sendo tanto maior quanto maiores as subdoses de glyphosate, triclopyr, carfentrazone-ethyl e de suas misturas (Tabela 2).

Entre os tratamentos, a deriva de glyphosate mostrou-se mais danosa ao eucalipto, seguida pelo carfentrazone-ethyl e triclopyr, respectivamente (Tabela 2). Entre as misturas, a combinação glyphosate + carfentrazone-ethyl ocasionou as maiores notas de porcentagem de intoxicação, em todas as épocas de avaliação (Tabela 2).

As médias referentes a altura, diâmetro e massa seca da parte aérea e da raiz das plantas e seus respectivos testes de médias encontramse na Tabela 3. Os herbicidas glyphosate, triclopyr, carfentrazone-ethyl e suas misturas afetou $(\mathrm{P}<0,05)$ a altura e a massa seca da parte aérea e da raiz das plantas de eucalipto, não sendo verificada diferença estatística para o diâmetro do caule $(\mathrm{p}<0,01)$.

A subdose de 172,8 $\mathrm{g} \mathrm{ha}^{-1}$ de glyphosate e a combinação de $86,4 \mathrm{~g}^{-1} \mathrm{a}^{-1}$ de glyphosate + $24 \mathrm{~g} \mathrm{ha}^{-1}$ de carfentrazone-ethyl proporcionaram a menor massa seca da parte aérea e da raiz de eucalipto (Tabela 3). Para altura de plantas, menores valores foram encontrados em plantas tratadas com as misturas de glyphosate + carfentrazone-ethyl (Tabela 3). A maior altura observada em plantas de eucalipto expostas a $172,8 \mathrm{~g} \mathrm{ha}^{-1}$ de glyphosate - que tiveram morte dos ponteiros por ação do herbicida - pode ser explicada pela emissão de novas brotações, que retomaram o crescimento das plantas.

Em trabalho semelhante, com deriva de glyphosate em clones de eucalipto, Tuffi Santos et al. (2005) relatam a emissão de brotações normais e com sintomas de intoxicação em plantas expostas às subdoses de 172,8 e $345,6 \mathrm{~g} \mathrm{ha}^{-1}$ de glyphosate. Dantas et al. (2001), 
trabalhando com glyphosate no controle da rebrota de cepas em diferentes clones de eucalipto, relatam o surgimento de brotações com sintomas de intoxicação.
Foram observados efeitos sinérgicos na avaliação da intoxicação das plantas causada pelas misturas entre glyphosate + triclopyr e glyphosate + carfentrazone-ethyl.

Tabela 2 - Porcentagem de intoxicação de plantas de eucalipto submetidas à deriva de herbicidas, aos 15, 30 e 45 dias após aplicação (DAA)

\begin{tabular}{|c|c|c|c|c|}
\hline \multirow{2}{*}{ Herbicida } & \multirow{2}{*}{$\begin{array}{c}\text { Dose p.a. } \\
\left(\mathrm{g} \mathrm{ha}^{-1}\right)\end{array}$} & \multicolumn{3}{|c|}{$\%$ de Intoxicação } \\
\hline & & 15 DAA & $30 \mathrm{DAA}$ & $45 \mathrm{DAA}$ \\
\hline testemunha (sem herbicida) & --- & $0,00 \mathrm{e}$ & $0,00 \mathrm{~d}$ & $0,00 \mathrm{e}$ \\
\hline glyphosate & 43,2 & $1,50 \mathrm{de}$ & $8,25 \mathrm{~d}$ & $4,50 \mathrm{e}$ \\
\hline glyphosate & 86,4 & 10,75 cde & $40,00 \mathrm{bc}$ & $27,50 \mathrm{~cd}$ \\
\hline glyphosate & 172,8 & $36,25 a b c$ & $65,00 \mathrm{a}$ & $66,25 \mathrm{a}$ \\
\hline triclopyr & 14,4 & 13,25 cde & $11,25 \mathrm{~d}$ & $7,50 \mathrm{e}$ \\
\hline triclopyr & 28,8 & $30,00 \mathrm{bcd}$ & $21,25 \mathrm{~cd}$ & $10,00 \mathrm{e}$ \\
\hline triclopyr & 57,6 & $36,45 \mathrm{abc}$ & $20,00 \mathrm{~cd}$ & $15,00 \mathrm{de}$ \\
\hline carfentrazone-ethyl & 12 & $25,00 \mathrm{bcd}$ & $23,75 \mathrm{~cd}$ & $28,75 \mathrm{~cd}$ \\
\hline carfentrazone-ethyl & 24 & $27,50 \mathrm{bcd}$ & $25,00 \mathrm{~cd}$ & $27,50 \mathrm{~cd}$ \\
\hline carfentrazone-ethyl & 48 & $38,75 \mathrm{abc}$ & $51,25 \mathrm{ab}$ & $51,25 \mathrm{ab}$ \\
\hline glyphosate + triclopyr & $43,2+14,4$ & $18,75 \mathrm{cde}$ & $21,25 \mathrm{~cd}$ & $15,75 \mathrm{de}$ \\
\hline glyphosate + triclopyr & $86,4+28,8$ & $42,50 \mathrm{ab}$ & $38,75 \mathrm{bc}$ & $47,50 \mathrm{~b}$ \\
\hline glyphosate + carfentrazone-ethyl & $43,2+12$ & $36,28 \mathrm{abc}$ & $36,25 \mathrm{bc}$ & $38,75 \mathrm{bc}$ \\
\hline glyphosate + carfentrazone-ethyl & $86,4+24$ & $57,50 \mathrm{a}$ & $60,00 \mathrm{a}$ & $65,00 \mathrm{a}$ \\
\hline $\mathrm{CV}(\%)$ & ---- & 22,72 & 38,74 & 12,35 \\
\hline
\end{tabular}

Médias seguidas pela mesma letra não diferem significativamente entre si pelo teste de Tukey a 5\% de probabilidade.

Tabela 3 - Massa seca da parte aérea e das raízes, diâmetro do caule e altura de plantas de eucalipto submetidas à deriva de diferentes herbicidas, aos 45 dias após aplicação

\begin{tabular}{|c|c|c|c|c|c|}
\hline \multirow{2}{*}{ Tratamento } & \multirow{2}{*}{$\begin{array}{l}\text { Dose p.a. } \\
\left(\mathrm{g} \mathrm{ha}^{-1}\right)\end{array}$} & \multicolumn{2}{|c|}{ Massa seca $(\mathrm{g})$} & \multirow{2}{*}{$\begin{array}{l}\text { Diâmetro } \\
(\mathrm{cm})\end{array}$} & \multirow{2}{*}{ Altura $(\mathrm{cm})$} \\
\hline & & Parte aérea & Raiz & & \\
\hline testemunha & --- & $84,63 \mathrm{a}$ & $42,42 \mathrm{a}$ & $0,72 \mathrm{a}$ & $46,25 \mathrm{ab}$ \\
\hline glyphosate & 43,2 & $72,74 \mathrm{ab}$ & $42,06 \mathrm{a}$ & $0,70 \mathrm{a}$ & $49,00 \mathrm{ab}$ \\
\hline glyphosate & 86,4 & $48,21 \mathrm{bc}$ & $33,88 \mathrm{ab}$ & $0,67 \mathrm{a}$ & $46,37 \mathrm{ab}$ \\
\hline glyphosate & 172,8 & $18,33 \mathrm{c}$ & $17,00 \mathrm{~b}$ & $0,69 \mathrm{a}$ & $51,00 \mathrm{a}$ \\
\hline triclopyr & 14,4 & $60,93 \mathrm{ab}$ & $34,54 \mathrm{ab}$ & $0,67 \mathrm{a}$ & $47,00 \mathrm{ab}$ \\
\hline triclopyr & 28,8 & $65,51 \mathrm{ab}$ & $42,95 \mathrm{a}$ & $0,70 \mathrm{a}$ & $43,37 \mathrm{ab}$ \\
\hline triclopyr & 57,6 & $46,59 \mathrm{bc}$ & $31,98 \mathrm{ab}$ & $0,68 \mathrm{a}$ & $44,25 \mathrm{ab}$ \\
\hline carfentrazone-ethyl & 12 & $72,42 a b$ & $33,45 a b$ & $0,61 \mathrm{a}$ & $48,12 \mathrm{ab}$ \\
\hline carfentrazone-ethyl & 24 & $62,94 \mathrm{ab}$ & $37,79 \mathrm{a}$ & $0,60 \mathrm{a}$ & $43,62 \mathrm{ab}$ \\
\hline carfentrazone-ethyl & 48 & $59,65 \mathrm{ab}$ & $32,19 \mathrm{ab}$ & $0,65 \mathrm{a}$ & $46,25 \mathrm{ab}$ \\
\hline glyphosate + triclopyr & $43,2+14,4$ & $54,66 \mathrm{abc}$ & $37,16 \mathrm{a}$ & $0,65 \mathrm{a}$ & $45,25 \mathrm{ab}$ \\
\hline glyphosate + triclopyr & $86,4+28,8$ & $34,23 \mathrm{bc}$ & $28,42 \mathrm{ab}$ & $0,57 \mathrm{a}$ & $42,50 \mathrm{ab}$ \\
\hline glyphosate + carfentrazone-ethyl & $43,2+12$ & $57,42 \mathrm{ab}$ & $31,98 \mathrm{ab}$ & $0,57 \mathrm{a}$ & $41,00 \mathrm{~b}$ \\
\hline glyphosate + carfentrazone-ethyl & $86,4+24$ & $17,89 \mathrm{c}$ & $27,01 \mathrm{ab}$ & $0,62 \mathrm{a}$ & $40,50 \mathrm{~b}$ \\
\hline $\mathrm{CV}(\%)$ & --- & 17,55 & 20,81 & 14,03 & 8,08 \\
\hline
\end{tabular}

Médias seguidas pela mesma letra não diferem significativamente entre si pelo teste de Tukey a 5\% de probabilidade. 
Os resultados demonstram os prejuízos da deriva de herbicidas não-seletivos no crescimento de plantas de eucalipto, alertando para os cuidados a serem tomados com a tecnologia de aplicação de herbicidas na cultura do eucalipto. O herbicida glyphosate e sua mistura com carfentrazone-ethyl foram mais prejudiciais que o triclopyr e suas respectivas misturas, quando da simulação da deriva. No entanto, os riscos com o triclopyr não devem ser desconsiderados, dada a sua alta atividade sobre plantas dicotiledôneas (Freitas et al., 2003; Rodrigues \& Almeida, 2005).

\section{LITERATURA CITADA}

BRADSHOW, L. D. et al. Perpectives on glyphosate resistence. Weed Tecnol., v. 11, p. 189-198, 1997.

COLBY, S. R. Calculating synergistic and antagonistic responses of herbicide combinations. Weeds, v. 15, p. 20-22, 1967.

CORRÊA, L. E. A.; BORGES, A. Glyphosate + carfentrazone-ethyl: controle de ervas problema. In: CONGRESSO BRASILEIRO DA CIÊNCIA DAS PLANTAS DANINHAS, 22., 2000, Foz do Iguaçu. Resumos... Foz do Iguaçu: Sociedade Brasileira da Ciência das Plantas Daninhas, 2000. p. 463.

CRUZ, C. D. Programa GENES: aplicativo computacional em genética e estatística versão Windows. Viçosa, MG: Universidade Federal de Viçosa, 2001. 442 p.

DANTAS, F. W. F.; SOUZA, A. J.; CIERO, A. D. Controle da rebrota de eucalipto em área de reflorestamento. In: SEMINÁRIO NACIONAL SOBRE HERBICIDAS E TECNOLOGIA DE APLICAÇÃO EM FLORESTAS, 2001, Viçosa-MG. Anais... Viçosa, MG: Sociedade Brasileira de Silvicultura/ Sociedade de Investigações Florestais, 2001. p.29-44.
FLINT, J. L.; CORNELIUS, P. L.; BARRETT, M. Analyzing herbicide interactions: a statistical treatment of Colby's method. Weed Technol., v. 2, n. 3, p. 304-309, 1988.

FREITAS, F. C. L. et al. Eficiência do triclopyr no controle de plantas daninhas em gramado (Paspalum notatum).

Planta Daninha, v. 21, n. 1, p. 159-164, 2003.

MAGALHÃES, P. C. et al. Efeito de doses reduzidas de glyphosate e paraquat simulando deriva na cultura do milho. Planta Daninha, v. 19, n. 2, p. 247-253, 2001.

MILLER, D. K. et al. Response of non glyphosate resistant cotton to reduced rates of glyphosate. Weed Sci., v. 52, p. 178-182, 2004.

RIBEIRO, G. T. Uso de herbicidas pré-emergentes em Eucalyptus sp. na região do cerrado. In: SEMINÁRIO TÉCNICO SOBRE PLANTAS DANINHAS E O USO DE HERBICIDAS EM REFLORESTAMENTO, 1988, Rio de Janeiro. Anais... Rio de Janeiro: SBS/ABRACAVE/SIF, 1988.

RODRIGUES, B. N.; ALMEIDA, F. S. Guia de herbicidas. 5.ed. Londrina: 2005. 591 p.

TOLEDO, R. E. B. et al. Faixas de controle de plantas daninhas e seus reflexos no crescimento de plantas de eucalipto. Sci. For., v. 64, p. 78-92, 2003.

TUFFI SANTOS, L. D. et al. Crescimento e morfoanatomia foliar de eucalipto sob efeito de deriva do glyphosate. Planta Daninha, v. 23, n.1, p.133-142, 2005.

YAMASHITA, O. M.; GUIMARÃES, S. C. Respostas de cultivares de algodoeiro a subdoses de glyphosate. Planta Daninha, v. 23, n. 4, p. 627-633, 2005. 